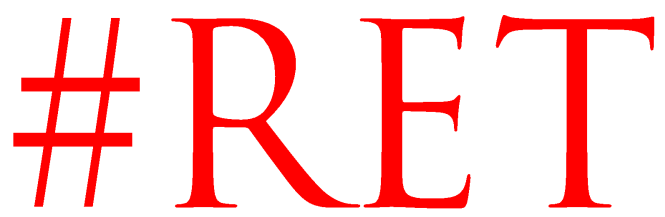

Revista Española de la Transparencia

Núm. 10. Primer Semestre 2020

ISSN 2444-2607. Págs. 19-29

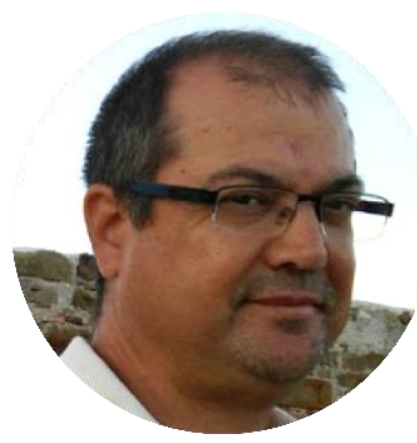

Severiano Fernández Ramos1

Catedrático de Derecho Administrativo

Universidad de Cádiz

\title{
Las infracciones relativas al ejercicio del derecho de acceso a la información pública.
}

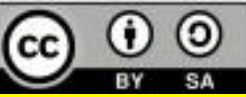

RECIBIDO: 2 de enero de 2020 ACEPTADO: 15 de enero de 2020

RESUMEN: El régimen sancionador puede cumplir, si está adecuadamente configurado, un papel complementario en la garantía del ejercicio del derecho de acceso a la información pública. Pero, como se trata de demostrar en este artículo, en lugar de tipificar la acción directa de denegar el derecho, es más operativo centrarse en las obligaciones formales que deben cumplir los sujetos obligados y, sobre todo, en garantizar frente a éstos la posición capital de los órganos independientes.

PALABRAS CLAVE: información pública, infracciones administrativas.

1 Catedrático de Derecho Administrativo de la Universidad de Cádiz. Cuenta con cuatro sexenios de investigación y ha desarrollado una intensa actividad investigadora en materia de transparencia y Buen Gobierno como antítesis a la corrupción. Es coautor (junto a José $M^{a}$ Pérez Monguió) de las siguientes monografías en la prestigiosa editorial Thomson ReutersAranzadi: La imparcialidad en el procedimiento administrativo (2012), La Ley de Transparencia, Acceso a la Información Pública y Buen Gobierno (2014), El Estatuto de los Altos Cargos (2016), El derecho de acceso a la información pública en España (2017), y Voz Pópuli. Consultas populares y procesos participativos (2019). 


\section{Severiano Fernández Ramos}

\section{Violations related to the exercise of the right of access to public information}

ABSTRACT: The sanctioning regime can fulfill, if properly configured, a complementary role in guaranteeing the exercise of the right of access to public information. But, as it is shown in this article, instead of typifying the direct action of denying the right, it is more operative to focus on the formal obligations that the obligated subjects must fulfill and, above all, on guaranteeing against them the capital position of the independent organs.

KEYWORDS: public information, administrative infractions. 


\section{LA GARANTÍA SANCIONADORA DEL DERECHO DE ACCESO A LA INFORMACIÓN PÚBLICA}

Vaya por delante que la garantía fundamental de la efectividad del derecho de acceso a la información pública, como derecho de ciudadanía, no es otra que la revisión de las resoluciones (expresas o presuntas) de los sujetos obligados (principal, aunque no exclusivamente, las Administraciones públicas) por un órgano funcionalmente independiente, lo que nos conduce a la importancia capital de los órganos de garantía y, en último término, de la justicia contencioso-administrativa².

Ahora bien, sin negar la relevancia fundamental de los órganos de garantía, la potestad sancionadora, como instrumento ordinario para la tutela de todo tipo de bienes jurídicos, también puede jugar un papel complementario en la protección de la efectividad del derecho de acceso a la información pública, tal como expresó el propio Consejo de Estado, en el dictamen sobre el proyecto de Ley 19/2013, de 9 de diciembre, de transparencia, acceso a la información pública y buen gobierno (en adelante, LTAIBG)3.

Sin embargo, como es notorio, la LTAIBG no contiene régimen sancionador alguno en relación con el derecho de acceso a la información pública. La única medida sancionadora prevista en la LTAIBG en materia del derecho de acceso a la información pública es la referida al incumplimiento del deber legal de resolver (y notificar) en plazo -art. 20.6-: «El incumplimiento reiterado de la obligación de resolver en plazo tendrá la consideración de infracción grave a los efectos de la aplicación a sus responsables del régimen disciplinario previsto en la correspondiente normativa reguladora». Medida disciplinaria que ya estaba prevista, con carácter general y con escaso éxito, por cierto, antes en la Ley 30/1992 y ahora en la Ley 39/2015, de 1 de noviembre, de Procedimiento Administrativo Común -art. 21.6-.

Esta omisión de la LTAIBG constituye, sin duda, una injustificable renuncia por parte del legislador básico a cumplir con su función de definición de un marco común de tutela del derecho del derecho acceso. Y ni qué decir tiene que, debido al principio de legalidad en materia sancionadora (y la consiguiente reserva de ley para la

\footnotetext{
${ }^{2}$ Vid. Fernández Ramos, S. (2018). «Los órganos de garantía ante la revisión judicial de su actuación». Revista Española de la Transparencia núm. 7: 19-28

3 Dictamen no: 707/2012, de 19 de julio de 2012: «Asimismo, podría introducirse en el título I un régimen sancionador que permitiera reprimir las conductas contrarias a las normas de transparencia que el anteproyecto recoge. Esta recomendación responde a la necesidad de reforzar el carácter imperativo que las normas de la proyectada Ley poseen, atendiendo al modo en que se encuentran formuladas, pues para que un mandato sea auténticamente obligatorio es necesario prever las consecuencias que en cada caso hayan de derivarse de su incumplimiento». A favor también de la tipificación de las conductas que comporten la obstaculización de la acción de la autoridad de tutela del derecho de acceso, se manifestó la Oficina Antifraude de Cataluña, Derecho de acceso a la información pública y transparencia, Colección de Estudios IntegriCat, núm. 4, abril, 2013, p. 173.
} 


\section{Severiano Fernández Ramos}

tipificación de infracciones y sanciones), esta omisión no puede ser subsanada mediante el (por cierto, aún pendiente) desarrollo reglamentario de la Ley estatal4.

Debido a esta censurable laguna de LTAIBG, como ley básica, las leyes autonómicas de transparencia tienen ante sí la posibilidad de ordenar un régimen sancionador propio, si bien debe tenerse presente que tal régimen se limita a su ámbito subjetivo de aplicación, lo que excluye, de entrada, la protección sancionadora del ejercicio del derecho de acceso frente al sector público estatal y demás entidades vinculadas al mismo (como las Corporaciones de Derecho Público de competencia del Estado). Sin embargo, lo cierto es que una buena parte de las leyes autonómicas, siguiendo el cómodo y nefasto ejemplo de la ley estatal, han omitido también tal régimen sancionador ${ }^{5}$.

Con todo, a partir de la Ley 1/2014, de 24 de junio, de Transparencia Pública de Andalucía, la mayoría de las leyes autonómicas sobre transparencia han incorporado un régimen sancionador, que en general sigue de cerca el establecido en la ley andaluza, salvo la Ley 19/2014, de 29 de diciembre, de transparencia, acceso a la información pública y buen gobierno de Cataluña, que contiene un diseño propio del régimen sancionador. Pues bien, a estos regímenes autonómicos se dedican las breves páginas siguientes, si bien nos limitaremos a la cuestión relativa a las infracciones que son objeto de tipificación, sin entrar en otras cuestiones sustantivas (como las sanciones, en su caso, previstas) ni menos aún en cuestiones procedimentales o de competencia para el ejercicio de la potestad sancionadora, aspectos todos ellos ciertamente muy relevantes en la prácticá.

\section{LAS INFRACCIONES EN MATERIA DE EJERCICIO DEL DERECHO EN EL MODELO ANDALUZ}

El modelo andaluz se basa en la distinción, presente en la propia LTAIBG -art. 20.6entre, de un lado, «faltas disciplinarias» que se imputan no ya a los sujetos obligados como tales (por tratarse de sujetos públicos), sino a las autoridades y al personal al servicio de las entidades del sector público, y, de otro lado, «infracciones administrativas», de las cuales son responsables las personas físicas y jurídicas (privadas) obligadas al suministro de información, de acuerdo con el art. 4 LTAIBG y preceptos concordantes de las leyes autonómicas.

\footnotetext{
${ }^{4}$ Sobre esta cuestión Teijeiro Lillo, Mํ E. (2019): «El régimen sancionador: una deficiencia pendiente en la Ley de Transparencia estatal», Actualidad Administrativa, Especial «Transparencia y lucha contra la corrupción», Nol, 1 de abr. de 2019.

${ }^{5}$ Ley Foral 11/2012, Ley 4/2013 Extremadura, Ley 3/2014 La Rioja, Ley 3/2015 Castilla y León, Ley 8/2015 Aragón y Ley 1/2016 Galicia.

${ }^{6}$ Véanse Pérez Monguió, J. Ma. (2015): «Régimen sancionador», en VV AA, Estudios sobre la Ley de Transparencia Pública de Andalucia, IAAP, Sevilla, pp. 291 y ss.; Villalba Cano, L. (2018): «El régimen sancionador en la Ley 1/2014, de 24 de junio, de Transparencia Pública de Andalucía y en la actividad del Consejo de Transparencia y Protección de Datos de Andalucia», en VV AA., Transparencia pública y Comunidades Autónomas, Tirant lo Blanch, Valencia, pp. 653 y ss.
} 


\section{Las infracciones relativas al ejercicio del derecho ...}

En relación con las faltas disciplinarias, se vienen a tipificar las siguientes:

- La denegación arbitraria del derecho de acceso a la información pública, generalmente calificada como falta muy grave7. Se trata, sin embargo, de un tipo de infracción de dificil aplicación. De entrada, a diferencia de lo que sucede con las sanciones penales, en relación con las cuales no existe prejudicialidad, al tratarse da sanciones administrativas debe entenderse que este supuesto requiere que un órgano de revisión, administrativo o jurisdiccional, haya declarado previamente y de modo firme que la denegación del derecho fue ilegal. Sin embargo, debe advertirse que los órganos de garantía del derecho, en general, aun cuando ordenen la comunicación de la información, evitan expresar que se ha actuado ilegalmente. Pero, además, es preciso que el órgano competente declare que la denegación, no sólo no fue conforme a derecho, sino que fue «arbitraria», lo que exige un plus, y que puede suponer un solapamiento con el tipo penal del art. 542 CP, relativo a impedir, a sabiendas, «el ejercicio de otros derechos cívicos reconocidos por la Constitución y las Leyes». Pero, en todo caso, lo cierto es que la extraordinaria dificultad para definir los límites del derecho de acceso frente a otros derechos y bienes jurídicos, como la protección de datos personales o el secreto comercial, determinan que sea plausible la alegación del error invencible, siendo suficiente para ello una adecuada motivación del acto. De este modo, en mi opinión, únicamente podría argumentarse que la denegación es arbitraria en dos supuestos: primero, en el caso de que la resolución expresa se encuentre desprovista por completo de motivación, y, segundo, cuando la motivación sea de modo manifiesto no pertinente, fruto evidente de fraude de ley en el cumplimiento del deber de motivación ${ }^{8}$. Además, debe observarse que la falta de motivación en caso de denegación presunta (mediante silencio desestimatorio) es irrelevante, pues -como ha manifestado la jurisprudencia- no cabe fundamentar la invalidez de un acto presunto desestimatorio en la ausencia de motivación del mismo, al ser esta omisión consustancial a la institución del silencio9. Para estos casos de silencio desestimatorio podrá acudirse a la falta que se indica seguidamente. Con todo, otro supuesto de denegación arbitraria del derecho de acceso puede ser aquel en el que existe una resolución expresa estimatoria, la cual sin embargo no se cumple en el plazo marcado por la Ley.

- El incumplimiento de la obligación de resolver en plazo la solicitud de acceso a la información pública, el cual inicialmente se califica de leve, pero si es reiterado se considera falta grave10. Como nos consta, es la única medida disciplinaria prevista en la LTAIBG -art. 20.6-. La diferencia es que la

\footnotetext{
7 Ley 1/2014 Andalucia -art. 52.2-, Ley 12/2014 R. Murcia -art. 43.2-; Ley 2/2015 C. Valenciana -art. 31.1; Ley 1/2018 Cantabria -art. 44.1.b)-, Ley Foral 5/2018 -art. 56.1-. Como señala Villalba Cano, L. (2018: 659), el fundamento último de esta infracción se encuentra en el principio de interdicción de la arbitrariedad de los poderes públicos ordenado por el art. 9.3 CE.

${ }^{8}$ Pérez Monguió, J. Ma (2015: 307).

9 STS 2-2-2010, Rec. 2878/2007.

${ }^{10}$ Ley 1/2014 Andalucía -art. 52.3 y 4-, Ley 12/2014 R. Murcia -art. 43.3 y 4-, Ley 12/2014 Canarias -art. 68.1.A)-; Ley 2/2015 C. Valenciana -art. 31.2 y 3-, Ley 1/2018 Cantabria -art. 44.2.b)-, Ley Foral 5/2018 art. 56.2-, Ley 10/2019 C. Madrid -art. 85.1.2 y 3-.
} 


\section{Severiano Fernández Ramos}

ley básica se limita a sancionar (como infracción grave) el incumplimiento reiterado, de modo que es más proporcionado el criterio del legislador autonómico de prever la sanción, aunque sea leve, del primer incumplimiento legal. Además, algunas leyes declaran qué se entiende por incumplimiento reiterado11. Asimismo, algunas leyes precisan que debe tratarse de un incumplimiento injustificado, pero lo cierto es, en caso de ampliación del plazo conforme a la LTAIBG -art. 20.1-, en rigor no existe incumplimiento alguno ${ }^{12}$.

- La falta de colaboración en la tramitación de las reclamaciones que se presenten ante el órgano autonómico de garantía del derecho, calificada generalmente como falta grave13. Debe recordarse que la LTAIBG -art. 24.3dispone que la tramitación de la reclamación se ajustará a lo dispuesto en materia de recursos en la Ley 30/1992, de 26 de noviembre, remisión que debe entenderse hecha ahora a la LPAC (D.F. $4^{\mathrm{a}}$ ), lo que estimo que supone la aplicación de la regla del recurso de alzada, según la cual el órgano que dictó el acto (expresa o presuntamente) objeto de impugnación debe remitir al órgano competente para resolver el recurso (en este caso, el órgano independiente de garantía) una copia completa y ordenada del expediente, junto con su informe -art. 121.1 LPAC. A este respecto, si bien la ausencia de remisión del informe por parte del sujeto obligado no entorpece la tramitación de la reclamación por el órgano de garantía (pues puede resolver perfectamente sin disponer del informe, que en la lógica de la reclamación, a diferencia del recurso de alzada, funciona realmente como alegación de «parte»), es indudable que la no disposición del expediente relativo a la solicitud de acceso a la información sí que supone un serio obstáculo a la labor de revisión del órgano de garantía, el cual se ve obligado a resolver la reclamación a partir de la resolución objeto de impugnación y, en el caso de silencio, sencillamente "a ciegas". Además, debe recordarse que la LTAIBG -art. 24.3- añade que «Cuando la denegación del acceso a la información se fundamente en la protección de derechos o intereses de terceros se otorgará, previamente a la resolución de la reclamación, trámite de audiencia a las personas que pudieran resultar afectadas para que aleguen lo que a su derecho convenga», y para cumplir este trámite de audiencia, que los tribunales están exigiendo por cierto con marcado rigor, los órganos de garantía precisan de la colaboración del sujeto obligado para la identificación de los terceros interesados. Por todo ello, estimo que la tipificación de esta infracción es muy acertada, pues es imprescindible para garantizar el adecuado funcionamiento del sistema de garantía pre-contenciosa del derecho de acceso a la información pública.

- El incumplimiento de las resoluciones dictadas en materia de acceso por el órgano autonómico de garantía del derecho en relación con las

\footnotetext{
${ }^{11}$ La Ley 1/2018 Cantabria -art. 44.4- entiende por reiteración la comisión de una infracción de la misma naturaleza, al menos, en dos ocasiones, sin que constituya reincidencia, al no haber sido declarado todavía por resolución firme en vía administrativa el primer incumplimiento.

12 Así Villalba Cano, L. (2018: 662) señala que en este se excluye, no ya la antijuridicidad, sino la tipicidad de la conducta.

${ }^{13}$ Ley 1/2014 Andalucia -art. 52.2-, Ley 12/2014 R. Murcia -art. 43.3-, Ley 2/2015 C. Valenciana -art. 31.2-, Ley Foral 5/2018 -art. 56.2-. La Ley 12/2014 Canarias -art. 68.1.A)- y Ley 1/2018 Cantabria -art. 44.2.c)- requieren que sea un comportamiento reiterado.
} 


\section{Las infracciones relotivas al ejercicio del derecho ...}

reclamaciones que se le hayan presentado, tipificado como falta muy grave ${ }^{14}$, o como grave o muy grave en función del grado de reiteración ${ }^{15}$. De entrada, debe entenderse que este incumplimiento no se produce hasta tanto la resolución no sea firme. Asimismo, una vez firme la resolución, sería oportuno que el órgano de garantía dirigiese un requerimiento específico al sujeto obligado, incluyendo la advertencia expresa de la posible responsabilidad sancionadora. Con todo, se trata de una infracción muy oportuna, pues tutela la posición de los órganos independientes como garantes institucionales del derecho de acceso a la información pública.

Por su parte, las infracciones administrativas previstas están todas, como es lógico, relacionadas con el incumplimiento de la obligación de suministro de información pública:

- La falta de contestación al requerimiento de información, que se suele calificar como falta grave16.

- El retraso injustificado en el suministro de la información o el suministro parcial $O$ en condiciones distintas de las reclamadas, son acciones tipificadas como faltas leves ${ }^{17}$.

- El suministro de la información incumpliendo las exigencias derivadas del principio de veracidad, calificado como grave18.

- El incumplimiento de la obligación de suministro de información que haya sido reclamada como consecuencia de un requerimiento del órgano de garantía o para dar cumplimiento a una resolución del mismo en materia de acceso, y que se suele calificar como muy grave19.

\section{LAS INFRACCIONES EN MATERIA DE EJERCICIO DEL DERECHO EN EL MODELO CATALÁN}

\footnotetext{
${ }^{14}$ Ley 1/2014 Andalucia -art. 52.2-, Ley 12/2014 R. Murcia -art. 43.2-, Ley 2/2015 C. Valenciana -art. 31.1-; Ley 4/2016 Castilla- La Mancha -art. 48.1-; Ley 1/2018 Cantabria -art. 44.1.c)-.

15 Más de tres veces, en un periodo de dos años, se tipifica de falta muy grave, y el simple incumplimiento reiterado como falta leve en la Ley 12/2014 Canarias -art. 68.1.A)- y en la Ley 8/2018 Asturias -art. 20.1-, donde la desatención dos veces se califica como grave, y una sola vez, como leve. Y la Ley Foral 5/2018 -art. 56.1- llega a exigir que el requerimiento se haya desatendido en más de cuatro ocasiones, en un periodo de dos años para su calificación como muy grave.

16 Ley 1/2014 Andalucía -art. 53.2-; en cambio, la Ley 1/2018 Cantabria -art. 46.1- califica esta infracción como muy grave.

${ }^{17}$ Ley 1/2014 Andalucía -art. 53.3-, Ley 10/2019 C. Madrid -art. 81.3-, Ley Foral 5/2018 -art. 57.3-. La Ley 1/2018 Cantabria -art. 46.3- exige que se trate de un retraso reiterado en el suministro de la información.

${ }^{18}$ Ley 1/2014 Andalucia -art. 53.2-, Ley Foral 5/2018 -art. 57.2-. La Ley 1/2018 Cantabria -art. 46.2exige que se trate de un incumplimiento de forma relevante.

${ }^{19}$ Ley 1/2014 Andalucía -art. 53.1-, Ley 12/2014 R. Murcia -art. 47-; Ley 2/2015 C. Valenciana -art. 33-, Ley 1/2018 Cantabria -art. 46.1-. La Ley 12/2014 Canarias -art. 69.1.B)- y la Ley 8/2018 Asturias -art. 21.1- y Ley 10/2019 C. Madrid -art. 85.1-, exigen para la calificación como muy grave que el incumplimiento sea reiterado más de tres veces, en un periodo de dos años, el incumplimiento dos veces, como grave, y una sola vez, como leve. Y la Ley Foral 5/2018 -art. 57.1- exige que se haya desatendido en más de cuatro ocasiones, en un periodo de dos años, el requerimiento expreso del órgano de garantía.
} 


\section{Severiano Fernández Ramos}

Por su parte, sin diferenciar formalmente entre faltas disciplinarias e infracciones, la Ley 19/2014 Cataluña contempla un abanico diverso y más amplio de infracciones con relación al derecho de acceso a la información pública -arts. 77.2 y 78.2-, algunas de las cuales han inspirado también a otras leyes autonómicas ${ }^{20}$ :

- Facilitar información relativa a los datos personales especialmente protegidos sin el consentimiento, expreso y por escrito, de las personas afectadas, la cual se tipifica como muy grave. Se trata de una falta que evidentemente se solapa con el régimen sancionador previsto en la legislación de datos personales.

- Ocultar la existencia de información pública para impedir su conocimiento y acceso, también calificada como muy grave21. Dado que esta ocultación únicamente se daría cuando el sujeto obligado declare, torticeramente, al responder a la solicitud, no disponer de la información solicitada, y dado que el término ocultar en cierra una innegable intencionalidad, este tipo infractor se solaparía con el delito de falsedad en documento público u oficial -art. $340.4^{\circ}$ Código Penal).

- Impedir u obstaculizar deliberadamente el acceso a la información en el caso de resolución estimatoria y en los casos de estimación por silencio, tipificada como muy grave, si bien debe recordarse que el Tribunal Constitucional ha declarado inconstitucional la opción por el legislador autonómico del silencio estimatorio en el procedimiento de ejercicio del derecho de acceso22.

- Dar información parcial, u omitir o manipular información relevante con el objetivo de influir en la formación de la opinión ciudadana, acción tipificada como infracción muy grave ${ }^{23}$. No obstante, la intencionalidad que parece exigirse a la acción ("con el objetivo de influir en la formación de la opinión ciudadana") puede desactivar, en la práctica, su aplicación.

- Facilitar intencionadamente información sometida a la aplicación de los límites establecidos en perjuicio de terceros, calificada como grave. Realmente, en este caso el bien jurídico protegido no es el derecho de acceso a la información pública, sino el bien protegido por el límite al ejercicio del derecho, y que, al menos en algunos casos, puede solaparse con otras infracciones (como las relativas a la protección de datos personales) e, incluso, el delito de revelación de secretos (art. 197 Código Penal).

- Omitir el trámite de audiencia de los terceros afectados por las solicitudes de acceso a la información pública, si los terceros están claramente identificados ${ }^{24}$. Esta infracción puede coadyuvar a que la tramitación de las solicitudes de acceso sea exquisita, evitándose problemas ulteriores, como

\footnotetext{
${ }^{20}$ Ley 4/2016 Castilla- La Mancha -art. 48.1- y Ley Foral 5/2018 -art. 56-.

${ }^{21}$ También Ley 4/2016 Castilla- La Mancha -art. 48.1-.

22 STC 104/2018, de 4 de octubre, en relación con la Ley 8/2015 Aragón. Vid. J. Sierra Rodríguez (2019), "Competencia estatal y silencio administrativo autonómico", VV . AA., Especial «Transparencia y lucha contra la corrupción», NI, 1 de abr. de 2019, Editorial Wolters Kluwer.

${ }^{23}$ También Ley 4/2016 Castilla- La Mancha -art. 48.1- y Ley Foral 5/2018 -art. 56.1-

${ }^{24}$ También Ley Foral 5/2018 -art. 56.2-.
} 


\section{Las infracciones relativas al ejercicio del derecho ...}

serian las alegaciones de mala fe por parte del sujeto obligado en caso de reclamación o, en su caso, en la vía contenciosa. Con todo, debe observarse que esta audiencia a terceros no es necesaria en caso de que proceda la aplicación de una causa de inadmisión (art. 18.1: "Se inadmitirá a trámite...").

- Desestimar sin motivación las solicitudes de acceso a la información pública ${ }^{25}$. Debe precisarse que esta infracción sólo es viable en caso de resolución expresa, pues en caso de silencio -como se ha señalado antesla jurisprudencia considera que la omisión del deber de motivación es inherente a la institución del silencio desestimatorio.

- Dar información incompleta o parcial, siempre que no esté justificado con el objeto de hacer compatible el derecho de acceso a la información pública con otros derechos. Debe recordarse que en los casos en que la aplicación de alguno de los límites previstos en el artículo 14 LTAIBG no afecte a la totalidad de la información, la comunicación parcial de la información es un deber legal del sujeto obligado (art. 16: "se concederá el acceso parcial"). De este modo, la circunstancia de que la comunicación parcial "no esté justificada" requiere un pronunciamiento previo y firme por un órgano de revisión, administrativo o jurisdiccional, en el que se declare que se omitió indebidamente parte de la información solicitada, todo lo cual determina que sea un tipo de difícil aplicación práctica.

- Facilitar deliberadamente la información en un formato o unas condiciones que impidan o dificulten manifiestamente su comprensión26. La exigencia de intencionalidad en la acción ("deliberadamente") unida a la circunstancia de que no existe un derecho ilimitado a elegir la forma o formato de la información, hacen pesar que estamos, de nuevo, ante un tipo infractor de difícil aplicación.

- Condicionar el acceso a la información al pago de una contraprestación en los supuestos de acceso gratuito27. Esta sí es una infracción muy plausible, pues la Ley determina claramente los supuestos de gratuidad en el acceso a la información.

- Incumplir los plazos establecidos para facilitar la información solicitada sin que exista una causa legal que lo justifique. Dado que el incumplimiento del plazo legal para resolver y notificar es ya de por sí una falta (la inmediatamente siguiente), no vemos la utilidad de ese otro tipo infractor.

- No resolver las solicitudes de acceso a la información de forma expresa y motivada dentro del plazo preceptivo, tipo que -como nos consta- se encuentra previsto en el modelo andaluz.

\section{OBSERVACIONES FINALES}

Debido a las tenues y complejas fronteras entre transparencia y privacidad, la infracción directa de denegación indebida del ejercicio del derecho de acceso a la información pública es de muy difícil aplicación práctica. Por este motivo, y

\footnotetext{
25 También Ley Foral 5/2018 -art. 56.2-. La Ley 10/2019 C. Madrid -art. 81.3- también tipifica como infracción leve la ausencia de motivación en la denegación de la información solicitada.

${ }^{26}$ También Ley Foral 5/2018 -art. 56.2-.

${ }^{27}$ También Ley Foral 5/2018 -art. 56.1-.
} 


\section{Severiano Fernández Ramos}

siguiendo parcialmente el criterio de la Ley 19/2014 Cataluña, es más operativo tipificar las actuaciones que suponen incumplimiento de deberes formales, como son los siguientes: el deber de resolver en plazo -art. 20.1 LTAIBG-, el deber de motivar en caso de resolución expresa -art. 20.1 LTAIBG-; el deber de facilitar la información en el plazo previsto en la resolución, total o parcialmente, estimatoria; así como el deber de dar audiencia a terceros interesados -art. 19.3 LTAIBG-. Asimismo, dado que la mayoría de las leyes autonómicas, a diferencia de la ley estatal, explicitan el deber de los sujetos obligados a ayudar y orientar a los solicitantes en la presentación de sus solicitudes de acceso a la información, también debería tipificarse como falta, aunque sea leve, el incumplimiento de dicho deber.

De otro lado, estimo muy oportunas las infracciones, previstas en el modelo de la ley andaluza, que tienen por bien jurídico directo a proteger la posición institucional del órgano independiente de garantía: infracciones de falta de colaboración en la tramitación de las reclamaciones, así como de incumplimiento de las resoluciones dictadas en materia de acceso por el órgano de garantía. Estas infracciones son cruciales para la efectividad del sistema de transparencia pública, y todo ello sin perjuicio, naturalmente, de atribuir al órgano de garantía poderes coercitivos propios.

Finalmente, en mi opinión, una laguna de la LTAIBG, y que no ha sido suplida por las leyes autonómicas, atañe a la conservación de la información pública. Con cierta frecuencia, el ejercicio del derecho de acceso a la información pública se ve frustrado, no ya porque se deniegue (expresa o presuntamente) el acceso en aplicación de alguno de los muchos límites legales, sino debido a la imposibilidad material de su ejercicio, pues la documentación que contenía la información ha sido destruida o sencillamente se ha perdido o se encuentra ilocalizable. Por esta razón, entiendo que las leyes de transparencia deberían prestar mayor atención a esta cuestión y, en tal sentido, debería contemplarse también la posibilidad de tipificar como falta la pérdida o destrucción de la información solicitada al margen de los procedimientos legalmente establecidos, al menos en aquellos casos en los que la legislación de archivos y documentos correspondiente no contemple esta actuación como infracción. 


\section{Las infracciones relativas al ejercicio del derecho ...}

\section{BIBLIOGRAFÍA}

Fernández Ramos, S. (2018). «Los órganos de garantía ante la revisión judicial de su actuación». Revista Española de la Transparencia núm. 7: 19-28.

Pérez Monguió, J. Ma. (2015): «Régimen sancionador», en VV AA, Estudios sobre la Ley de Transparencia Pública de Andalucia, IAAP, Sevilla.

Sierra Rodriguez, J. (2019), "Competencia estatal y silencio administrativo autonómico", VV. AA., Especial «Transparencia y lucha contra la corrupción», No I, 1 de abr. de 2019, Editorial Wolters Kluwer.

Teijeiro Lillo, Ma E. (2019): «El régimen sancionador: una deficiencia pendiente en la Ley de Transparencia estatal», Actualidad Administrativa, Especial «Transparencia y lucha contra la corrupción», No I, 1 de abr. de 2019.

Villalba Cano, L. (2018): «El régimen sancionador en la Ley 1/2014, de 24 de junio, de Transparencia Pública de Andalucía y en la actividad del Consejo de Transparencia y Protección de Datos de Andalucia», en VV AA., Transparencia pública y Comunidades Autónomas, Tirant lo Blanch, Valencia. 
